\title{
Transdisciplinaridade e Universidade ${ }^{1}$
}

\section{Patrick Paul}

Eu não sabia muito bem, para dizer a verdade, quando foi proposto o convite, quais seriam os centros de interesses mais específicos ligados ao meu próprio caminho de pesquisa. Mas, com as interaçóes que tivemos hoje de manhã ${ }^{2}$, essas possibilidades de interações são de fato extremamente importantes, porque há muitos anos eu já me questiono sobre a questâo da objetividade dos tratamentos ou a respeito da desumanização da medicina, sobre as questôes ligadas à relação médico-paciente, sobre a questão da diferença ou não entre a doença e o doente, e depois sobre a questão da interação da relação entre profissionais de saúde.

Então, de fato, especialmente no campo da educação terapêutica, essa questão das relações pluridisciplinares é central. Então vejam que são campos muito vizinhos aos campos de vocês. Correndo o risco de parecer muito intelectual e formal, mas isso não vai se estender por muito tempo, fiquem tranquilos, acho que é preciso inicialmente recolocar o problema da pesquisa na área da saúde, numa abordagem que raramente é iniciada no campo médico, que é o campo epistemológico.

A epistemologia é uma palavra que nunca ouvi falar durante os meus estudos de medicina, por exemplo, mas que postula que todo conhecimento náo se apoia na verdade a priori, ou seja, se apoia em postulados de partida. Quer dizer que em todo o conhecimento há uma definição a priori da maneira a partir da qual eu vou proceder para observar as coisas e para dar sentido a elas.
No mundo da medicina, ou no campo científico em geral, essa maneira de proceder remonta ao meio do século XIX, quando houve aquilo que se chamou de mudança de paradigma ou ruptura epistemológica, que se seguiu a uma ruptura anterior que foi aquela do dualismo cartesiano que ocorreu no século XVII e que ela mesma já havia consideravelmente modificado o pensamento epistemológico antigo, que era uma epistemologia holista como, por exemplo, a gente encontra na acupuntura. No caso da acupuntura o céu está ligado à Terra e ao homem.

Então houve essa primeira ruptura com Descartes, depois uma segunda com Augusto Comte, e esse ponto é fundamental, porque a partir da metade do século XIX, quando vai aparecer a produção científica tal qual a conhecemos hoje, ou seja, que tem a tendência - e eu vou voltar a falar disso em seguida -, a ir em direção à objetividade científica, em direção ao reducionismo metodológico; por exemplo, o reducionismo vai estar na base de toda a organização disciplinar das universidades.

Vejam que são desafios muito importantes, e esses desafios justamente nos dias atuais em alguns campos, e em especial na área da saúde. Também poderíamos dizer o mesmo no caso do meio ambiente, da economia e outros campos, sem dúvida... Estamos numa sociedade na qual os problemas se tornam cada vez mais complexos e onde esse reducionismo metodológico não pode funcionar. Um dos desafios atuais da sociedade é estabelecer relações e ligaçóes entre as coisas.

\footnotetext{
${ }^{1}$ Conferência realizada pelo Prof. Patrick Paul, na Universidade Federal de São Paulo (UNIFESP), em 04/11/2010

Transcriçáo: Dalva Alves. Técnica em Assuntos Educacionais, Pró-Reitoria de Graduação da UNIFESP

Traduçáo: Prof. Américo Sommerman

Revisão final: Prof. Dr. Afonso Carlos Neves, Setor de Neuro-Humanidades, Disciplina de Neurologia da UNIFESP

Nota do Editor: A intermediaçấo do encontro entre os professores Afonso e Patrick foi feita por Dalva Alves. A intermediação do convite da UNIFESP para o Prof. Patrick e encontro com professores da Comissão de Residência Médica (Prof. Gilmar Fernandes do Prado) e Comissão de Residência Multiprofissional (Profa. Dra. Sônia) foi feita pelo Prof. Afonso. A apresentação dos Prof. Patrick Paul e Prof. Américo Sommerman ao público presente foi feita por Vera Salvadori (Assessora de Relaçóes Internacionais da UNIFESP). O Prof. Patrick fez a palestra em francês e a tradução para o português foi feita pelo Prof. Américo.
}

${ }^{2}$ Reunião realizada com o coordenador da Comissão de Residência Médica da Unifesp (Prof. Gilmar Fernandes do Prado), vice-coordenadora da Comissão de Residência Multiprofissional da Unifesp (Profa. Maria Ines Rebelo Gonçalves), Coordenador da Comissão de Residência em Saúde da Unifesp (Prof. Ramiro Anthero Azevedo), Chefe do Setor de Neuro-Humanidades da Disciplina de Neurologia da Unifesp. 
Então eu dizia que em primeiro lugar é preciso nos questionar a respeito da epistemologia; quer dizer, o que constrói a ciência atual? E nessa ciência atual há duas hipóteses, ou seja, dois postulados não verificáveis, mas que não nos pedem que verifiquemos. É o ponto de vista a partir do qual nos colocamos, mas poderia haver outros pontos de vista.

Então há duas hipóteses, uma hipótese que é chamada de ontológica, que conduz à objetividade; quer dizer que se considera o real como independente dos observadores, por exemplo, a cadeira existe quer eu esteja aqui ou não diante dela. Mas eu vou contradizer essa hipótese com uma outra fenomenológica. É que na verdade a cadeira só existe porque eu a vejo. As duas proposiçôes estão corretas, no entanto as consequências de cada uma delas são muito diferentes uma da outra: num caso a realidade existe enquanto tal e na outra ela inclui o sujeito que a observa.

A tese ontológica começou a ser abalada na história das ciências com a física quântica, pois a física quântica mostrou essa interação entre observador e observação. Outro ponto dessa hipótese ontológica é que partimos de um postulado de que a soma dos conhecimentos vai poder recompor a totalidade da realidade. Subjacente à hipótese ontológica há uma metodologia, e a metodologia é o reducionismo.

Esse reducionismo consiste em dizer que a gente não pode compreender o real como um todo, o qual é muito amplo; então é preciso recortar esse real e definir objetos em campos disciplinares. Mas a medicina não vai ser a psicologia, ou a sociologia, ou a matemática; na medicina a nefrologia não será a pneumologia etc. Então vocês veem que o problema das disciplinas é que para existirem é preciso que elas definam o seu próprio campo. E, enquanto definição de campo, a própria definição da disciplina exclui as outras, porque, por exemplo, a pneumologia não é tudo o que eu excluo e não é tudo o que é a pneumologia.

E há, também, em subjacência, uma outra metodologia, que é o princípio de razão suficiente; então, na verdade, é a lógica aristotélica que determina um princí- pio de não-contradiçãa, o terceiro excluído, e um princípio de identidade exclusivo. Se eu defino uma coisa, então essa coisa é essa coisa e ela exclui tudo aquilo que não é isso. O terceiro excluído e o princípio de identidade que está relacionado a ele, numa outra hipótese igualmente, é o que se chama de hipótese determinista; quer dizer que uma coisa remete sempre a algo que lhe está anterior. Não é por acaso que a visão de Pasteur se desenvolveu logo depois disso. Quer dizer, que se uma pessoa está doente, nós vamos buscar uma causa anterior que possa explicar de algum modo a sua patologia.

Então temos duas hipóteses: a ontológica e a determinista e duas metodologias de base: reducionismo e razáo suficiente. Quando olhamos bem os indicadores hoje, em vários campos, percebemos também que esses princípios começam a ser contestados.

No que diz respeito à hipótese determinista, podemos ver no atual campo da sistêmica, que além do determinismo há também uma teleologia. Quer dizer que um sistema não está só organizado com causas anteriores, ele também está concebido para uma certa finalidade.

Vejam que o que parece muito simplista como questionamento tem consequências fundamentais. Quer dizer que, se uma doença ou um doente é interrogado a partir de uma perspectiva positivista, esta vai se refletir sobre a doença, como ligada a algo anterior e, imaginando que o tratamento seja efetivo, o objetivo vai ser encontrar o estado anterior de saúde. É um pouco como se a experiência mesma da doença fosse apagada; e nesse caso não há um questionamento a respeito do sentido da doença; ou seja, qual é a finalidade da doença? Essa interrogaçáo já remeteria muito mais a uma dimensão humanista. O que eu quero dizer com essa primeira reflexão é que, desde o momento em que nos posicionamos de certa maneira, nós vamos abrir certos "possíveis" e vamos fechar outros.

Um outro campo que é muito vizinho a esse conhecimento científico é a questão da metodologia que é mais frequentemente utilizada, que é uma metodologia que é chamada de hipotético-dedutiva. O princípio da razão suficiente, da hipótese determinista, está presente no campo das ciências e da pesquisa. Quer dizer que há 
sempre uma causa anterior, há sempre uma verdade, que vai se fazer "tentar evoluir", sem o que a pesquisa não teria sentido. Mas aí nos baseamos sobre um modelo anterior e a partir desse modelo, de maneira um pouco descendente, nós vamos construir conhecimentos para analisar o campo de pesquisa.

Nas pesquisas de doutorado, por exemplo, nas ciências humanas, primeiro vão ser determinados conceitos, mas esses conceitos já são anteriores, já estão reconhecidos pela ciência de maneira a poder analisar um problema. Esse é o método hipotético-dedutivo.

Mas nessa hipótese colocada (hipótese determinista), por exemplo, náo se leva de modo algum em conta, a realidade de base do campo enfocado. $\mathrm{Na}$ interação que eu tive há pouco, na reunião anterior, foi uma das perguntas que eu coloquei para o grupo. O grupo estava reunido num contexto de residência multiprofissional, então vejam que há esse nível descendente, há decisóes do Ministério da Saúde ou da Educação, há apropriaçóes científicas, depois vai se tentar criar um diálogo pluridisciplinar, mas sempre há o "a priori" do terreno, do campo, que não são apreendidos apenas com esse funcionamento.

Eu tentei apreciar esses "a priori” na organização da sala: todos os alunos estão mais para o fundo e os professores estão mais no espaço da frente, pessoas que estáo na hierarquia mais acima. Então a gente pode avaliar os "a priori” nos quais nós estamos nos construindo, os quais normalmente a gente nem percebe.

Eu sugeri que se fizesse uma experiência separando as pessoas em grupos profissionais e que cada um falasse sem mentir o que pensa da outra profissáo; e muitas surpresas iriam aparecer. Então, nesse caso, já não se trata de metodologias hipotético-dedutivas, não se obedece então o modelo tentando fazer com que a coisa avance, mas tentamos fazer emergir o contrário daquilo que se chama de metodologias indutivas a partir do próprio campo, apreciar os indicadores que vão ajudar o conhecimento, para que depois se possa articular as duas metodologias num campo científico. Vejam que se questionar a respeito daquilo que constrói a ciência pode ser pertinente, ainda mais nas dificuldades atuais da sociedade.
Quando vamos mais em direção ao campo científico, é preciso já evitar os falsos problemas. Quer dizer que no campo da medicina e da saúde é preciso fazer a separação entre o que pertence estritamente ao campo científico hipotético-dedutivo e que não devemos de modo algum contestar, e aquilo que poderia ser contestado nessa metodologia científica hipotético-dedutiva.

Quer dizer que ter uma tecnologia melhor, scanner, ressonância magnética, não há porque contestar isso; tratar um infarto colocando um stent, não se deve contestar isso; tudo o que é do campo das urgências cirúrgicas, toda a tecnologia que vai ser utilizada, isso é incontestável. Tudo o que for do registro da infectologia, das doenças agudas, também não devem ser contestados. O que se deve compreender é que nesse novo questionamento, alguns campos científicos e médicos, definidos pela abordagem positivista, têm a sua pertinência e continuam a conservar essa pertinência; quer dizer que numa mudança de paradigma se trata na verdade de colocar questóes a respeito daquilo que não está funcionando, mas não de questionar aquilo que está funcionando. Isso é muito importante!

Então, o que não está funcionando? $\mathrm{O}$ que não funciona diz respeito, em primeiro lugar à questão muito ampla das doenças crônicas. As doenças crônicas se tornam cada vez mais amplas, em maior número estatisticamente, porque há uma melhora da qualidade de vida da sociedade, as pessoas morrem em idades mais avançadas do que antes e há cada vez mais doenças sociais.

Todas as doenças metabólicas, muitas doenças cardiovasculares, sem dúvida, também psiquiátricas, todas as patologias ambientais, sem dúvida também a oncologia - também é preciso haver um questionamento a respeito dessa explosão de câncer. Então vemos que há campos nos quais muito concretamente minhas palavras se apoiam, por exemplo, na estatística. E há campos que escapam às possibilidades da ciência atual de fato.

É preciso compreender que esse escape, no caso, por exemplo, da diabetes, não se trata tanto de dizer que o que escapa é o tratamento, que atualmente temos co- 
nhecimento suficiente para compreender e prevenir a grande maioria dos riscos e agravamento posterior, temos moléculas eficazes para o tratamento. O problema é o que escapa. E o que escapa não é a doença, é o doente.

Concretamente, nas estatísticas, ao menos nas estatísticas francesas, imagino que aqui seja semelhante, há aproximadamente $30 \%$ das pessoas que vão seguir efetivamente as prescriçôes, sejam medicamentosas, sejam higienodietéticas - que são necessárias nesse caso; e, ao contrário disso, $70 \%$ das pessoas não se tratam bem, o que vai ter consequências maiores, em primeiro lugar para a própria qualidade de vida do paciente, para todo o trabalho familiar e profissional e, em terceiro lugar para a sociedade, porque isso custa dinheiro. Então não são economias de saúde, mas são custos de saúde suplementares.

Vejam que essas interrogaçóes são muito reais e também é a realidade da presença de vocês aqui. Uma das questôes muito importantes é que percebemos atualmente, com essa complexificação muito grande da sociedade, que nenhum profissional de saúde ou de outra área, pode permanecer isolado no seu canto. Vê-se cada vez mais o imperativo de interação profissional. Poderíamos dizer no campo da saúde, entre os profissionais que estão aqui presentes; mas na saúde pública, por exemplo, também seria talvez necessário se criar grupos, não só de profissionais de saúde, mas de profissionais ligados ao meio ambiente, ao urbanismo, à economia etc., porque tudo está interligado.

Então nos encontramos diante de um segundo problema que é o da comunicação e da relação entre as disciplinas.

Vejam que nesses dois questionamentos que se colocam, as questóes que se colocam fazem com que reemerja a questão do sujeito. Quer dizer que o sujeito na metodologia positivista foi apagado da ciência, tudo o que é sujeito, subjetividade, é considerado como artefato não científico, pois neste postulado a verdade é a objetividade. Mas de tanto tentar construir uma ciência apoiada na objetividade, ou seja, no objeto, se esqueceu do sujeito e agora o sujeito reaparece com força nos problemas da sociedade.
Então vejam que quando nos questionamos vão surgir diferentes níveis de questionamentos. Há um primeiro nível que é o nível conceitual: ousar colocar em questão a ciência atual ou ao menos em alguns dos seus campos, o que não é uma coisa fácil porque a ciência é tautológica. $\mathrm{O}$ que quer dizer que ela só considera verdadeira a sua própria produção. Ou seja, ela é ao mesmo tempo juiz e árbitro. Então é difícil questioná-la. Então ela é que vai determinar o que é verdadeiro e o que é falso. E a partir do momento em que ela é muito dogmática, então é apenas nas zonas de fronteira, entre os campos disciplinares, que esses questionamentos podem se fazer; quando esses questionamentos ocorrem, o verdadeiro problema - e nós falamos antes na reunião anterior -, é que em geral nós sentimos falta da epistemologia e da metodologia que permitiria esse novo questionamento.

A gente vê que esse questionamento é atual - e a presença de vocês mostra isso - mas não é fácil tratar verdadeiramente esses problemas que se colocam. Vejam que aquilo que está sendo colocado como problema, de alguma maneira, é anticientífico, porque se trata de estabelecer uma comunicação entre disciplinas, onde a definição mesma é que elas estejam separadas umas das outras.

Vejam as questóes que se colocam. A segunda colocação em questáo já não é de ordem conceitual, mas pragmática. Quer dizer que serão colocadas questóes nesse questionamento sob o imperativo de economias de saúde, sobre a questão da observância do tratamento, por exemplo, do diabetes ou das doenças crônicas; então são questôes ligadas ao paciente, sobre a sociedade, a economia, sobre o próprio paciente e depois sobre a nossa própria eficiência profissional, porque é um pouco frustrante para um profissional, que tem instrumentos para tratar, encontrar $70 \%$ dos casos numa situação de fracasso, de impasse e de não conseguir.

Isso coloca em subjacência uma questão metodológica, que é aquela do diálogo. Diálogo entre terapeuta, ou médico, e paciente, ou diálogo entre os profissionais, eles mesmos entre si. 
Uma questão também subjacente, que também muito faz parte do questionamento sobre a saúde, é o questionamento ético. Que direito eu tenho enquanto profissional de determinar o que é justo para uma outra pessoa? É uma outra questão, mas que está muito ligada com o que eu venho dizendo até aqui. Tem relação com o método hipotético-dedutivo e o método indutivo. É uma espécie de aplicação desses métodos.

$\mathrm{Eu}$, enquanto profissional, estou construído a partir desse método hipotético-dedutivo. Então eu tenho meus valores, eu tenho minhas certezas, eu tenho minhas ferramentas, minhas capacidades reais, eu tenho diante de mim um paciente/um doente, ele tem a sua liberdade - então isso é a realidade do indutivo, é da realidade do campo, ele mesmo - então eu penso que minhas boas palavras e minha prescrição vão ser suficientes para resolver a questão, o problema; mas o que vai ocorrer é que eu só vou conseguir tratar a minoria das pessoas de maneira eficaz; entấo se trata de recolocar, em parte, em questão a minha metodologia de aproximação em relação ao paciente.

Então como funciona um terapeuta? Enquanto médico eu não posso falar em nome de uma enfermeira, de um enfermeiro ou de um fisioterapeuta, mas eu posso imaginar que seja semelhante, porque todos nós somos construídos de maneira semelhante. Eu tenho todo meu ativo, meu saber anterior, a causalidade anterior, eu tenho todo meu ativo profissional; por exemplo, enquanto médico, eu tenho esse ativo, eu vou interrogar o paciente, tenho um olhar para o paciente, mas na verdade o meu olhar vai ser muito seletivo mesmo que eu não tenha consciência disso, porque eu vou selecionar, naquilo que ele diz, o que me interessa. Meu objetivo é dar um diagnóstico, então eu vou selecionar a doença naquilo que ele fala, talvez, diagnósticos diversos.

Então, de alguma maneira, eu vou apagar a realidade da pessoa. A realidade (da pessoa) que não me interessa eu vou apagar, para fazer aparecer apenas a realidade da doença - e na verdade eu vou tratar uma doença. Mas a partir desse momento eu já não vou poder tratar um doente, porque eu não me coloquei questóes a respeito do doente, eu não perguntei o que ele pensa da sua doença, como ele vai sentir a falseabilidade de uma coisa ou de outra.

Como vocês vão querer que um doente, por exemplo, diabético, como falei há pouco, como ele vai se comportar? Eu vou dizer a ele: você tem que prestar atenção na sua alimentação. Se ele não prestar atenção nessa alimentação, nesse tratamento, dentro de alguns anos ele apresenta risco de ter uma retinopatia, uma arteriopatia, uma neuropatia. Ele tem a informação, vocês também, vocês todos têm a informação - relação sexual protegida - eu não estou fazendo de fato esta pergunta - mas todos vocês têm relações sexuais protegidas? A gente não faz isso (a pergunta)! É fácil dizer que o doente é um imbecil, que ele não compreendeu, mas todos nós fazemos isso.

Então, essa pessoa entendeu intelectualmente o discurso; às vezes, é verdade, ele não entendeu direito, mas supondo que ele entendeu, no entanto, nessa noite do mesmo dia da consulta, ele recebe os amigos para jantar... Vocês pensam que ele vai dizer para os amigos: vocês comam tudo isso, eu vou fazer o meu regime?! Não! Porque não é só a doença que vai interferir.

$\mathrm{Na}$ antropologia americana, fala-se de três níveis da doença que estão em interação: há uma doença biológica que é chamada de disease; há uma doença psicológica que se chama de illness - pessoas que podem estar sempre doentes, porque de algum modo é através da doença que ele se reconhece, e talvez se você tiver uma resposta para curá-lo ele já não volte mais - depois há uma doença que é chamada de sickness, que é um pouco isso, no caso da diabetes: é uma doença social. Entâo a gente se estigmatiza em relação ao social ou, ao contrário, a gente vai querer ser como os outros.

Todos esses elementos devem ser levados em conta, e muitos outros. Peçam para um diabético fazer exercícios físicos, mas se essa pessoa não tem meios de locomoção, se ela está num lugar cercado de prédios, numa atmosfera totalmente poluída, se não tem espaço para esse exercício ela não vai poder aplicar isso. São questões simples, mas que são fundamentais num ato terapêutico, mais uma vez, no caso das doenças crônicas. 
Mas quando a gente faz um diagnóstico de diabetes, a gente não vai perguntar sobre todos esses outros parâmetros - O que a pessoa pensa da sua doença?... Como ela vive a sua doença?... O que vai ser mais fácil ou mais difícil? Por quê? A gente pensa - a gente está aí no método hipotético-dedutivo - que aquilo que a gente diz como verdade vai ser tomado pelo outro como verdade. Então vejam que são questôes muito simples, mas que são importantes. São questóes que podem ser colocadas, por exemplo, sobre a questão da observância. É preciso aprender metodologias que vão permitir encontrar a pessoa de outra maneira. Essas metodologias existem, mas a gente não aprende na nossa formação, assim como não aprendemos o diálogo interprofissional.

Mantendo-me nessas questóes bem gerais, eu não tenho outra intenção, agora, nesse momento... O método hipotético-dedutivo, sem que tenhamos consciência, visa a uma ausência de autonomia do paciente. Tudo é feito no diagnóstico e no tratamento para tratar a doença; então, de algum modo, para não levar em conta o paciente, e para que a relação de terapeuta e paciente nesse caso seja uma relação assimétrica - há alguém que tem o poder, o conhecimento e outro que não tem e deve aceitar. Essa assimetria se aprende também facilmente em todas as relaçôes interprofissionais. A gente pode falar de pluriprofissionalidade, mas na verdade, há uma hierarquização - e seria importante a gente olhar para isso e questionar isso, e essa hierarquização pode ser legitimada, e eu não estou contestando isso -, vai ter consequências e a primeira delas é a não-autonomia.

Ora, se quisermos ir na direção de economias de saúde é preciso que o paciente seja autônomo, é preciso estabelecer uma relação que permita essa autonomia, que a torne possível, mesmo que a estimule, que a dinamize; seria a mesma coisa nas formaçóes interprofissionais. Se a gente não emprega uma metodologia de trabalho conjunto que favoreça essa autonomia, só vai haver uma adesão superficial, o que quer dizer que - e eu volto aí à questão do paciente -, é verdadeiramente importante aprender a colocar essa dimensão da autonomia; o que quer dizer que, de algum modo, toda ação terapêutica nessa nova abordagem, que para mim remete a questão da educação terapêutica - e eu não falei muito a respeito da educação terapêutica -, isso vai remeter à noção de contrato, mas que é um contrato que é recíproco.

Quer dizer que não se trata tanto de tratar um paciente, sobretudo nos contextos de doenças crônicas, porque não há as urgências das doenças agudas. Então temos tempo; mas trata-se de estabelecer um contrato educativo com essa pessoa, de maneira que, ao longo do tempo, haja objetivos negociáveis, nos quais a autonomia do paciente seja solicitada. E poderíamos dizer a mesma coisa nas relaçóes interprofissionais.

É preciso que cada um tenha sua palavra a dizer, que não haja um elemento que seja prioritário em relaçáo ao outro, mas que, cada um, com aquilo que ele é e com suas competências, possa determinar objetivos comuns, eventualmente renegociados ao longo do tempo. Quer dizer que toda forma de contrato educativo pressupóe, num momento ou no outro, um balanço educativo, um balanço no âmbito de uma relação interprofissional, por exemplo; e esse balanço, essa constatação vão lançar novas etapas.

Vejam nessa dinâmica como é importante trazer suas informações, suas próprias riquezas e suas próprias competências, e nesse sentido as competências disciplinares não são questionadas, elas não são negadas, mas se trata de questionar as metodologias de interação, de maneira a poder ir em direção a certos objetivos decididos conjuntamente.

E aí já estamos implicitamente, por exemplo, na metodologia transdisciplinar, que é chamada nessa metodologia de terceiro incluído. Quer dizer, eu tenho os meus próprios valores, não se trata de que eu deva renunciar aos meus próprios valores como profissional de saúde, mas o paciente, ou o outro profissional, tem os seus próprios valores, seu próprio olhar, e então a partir daí isso quer dizer que a cadeira não é mais a cadeira, porque a cadeira está sempre ligada a minha própria observação da coisa e de maneira muito objetiva, aliás. É possível entẫo dizer que a cadeira é uma abstração, porque se a gente colocar uma cadeira aqui na frente, cada um de vocês vai 
vê-la de maneira diferente, não vai ser o mesmo ângulo de percepção, vocês não vão ter a mesma qualificação, alguns vão achar que essa cadeira é muito prática, outros vão falar que falta estética a ela, outros vão preferir mais cor, outros vão preferir que fosse de madeira, de maneira que há sempre o implícito qualificativo. Aí então aparece a abordagem fenomenológica das coisas.

Então vejam que a mudança de paradigma, vamos considerar que em relação à hipótese ontológica, é talvez a hipótese fenomenológica, que vai permitir corrigir as coisas. Quer dizer que em vez de considerar que a realidade é independente dos observadores, pode-se postular que a realidade é dependente dos observadores. E vejam que essa simples mudança de postulado abre campos extremamente diferentes, porque nesse momento a maneira do doente ver a si mesmo é tão válida quanto a nossa. É ele que vive com a sua vida, não somos nós. Às vezes ele tem muito mais saberes sobre a sua própria vida do que nós. Então se deve levar em conta essa realidade dele como sendo tão importante como a nossa. É fundamental, mas isso poderia ser muito esquizofrênico, se nós não tivermos uma maneira de tratar essa separação, porque aí ele fica na verdade dele e eu fico na minha e aí, bom, acabou.

Entáo essa questão do contrato educativo ou da linguagem comum são maneiras pelas quais é possível construir conjuntamente terceiros incluídos, num mesmo nível de realidade. Para mim essa é a definição, um dos olhares possíveis sobre a interdisciplinaridade.

Então vejam que recolocar em questão a hipótese ontológica é fundamental, mas recolocar em questão essa hipótese ontológica postula que, subjacentemente, à abordagem fenomenológica, vamos ser constantemente confrontados de maneira fundamental com um buraco negro do conhecimento. Quer postular que algo possa se tornar comum, encontrar o paradoxo e as contradiçóes, e os conflitos e as oposiçóes remetem a um buraco negro.

Eu sei, por exemplo, o que eu devo fazer enquanto profissional de saúde, mas depois o paciente não quer se tratar e não quer fazer o regime. Eu devo respeitar isso; de todo modo eu não tenho escolha, eu tenho que respeitar. Mas então vejam o buraco negro... O que a gente faz? Mas saibam que com o doente é a mesma coisa. Ele escuta o que a gente está falando, mas ele está diante do mesmo buraco negro, só que a gente achou que ele nos compreendeu. Então vejam fundamentalmente, essa abordagem fenomenológica remete a esse buraco negro. Mas esse buraco negro pode ir se preenchendo, ao menos parcialmente, metodologicamente, e é o que pode ao mesmo tempo ser criador de conhecimento, mas ao mesmo tempo, no fundo, postular que nessas abordagens complexistas e sistêmicas, todo o real está sempre aberto. Se não houvesse um buraco negro, isto postularia que o real é fechado.

Igualmente, por exemplo, vamos questionar o reducionismo e o reducionismo vai ser substituído pela complexidade. Isto quer dizer que é preciso entender a pessoa não mais como objeto - o reducionismo apaga o sujeito para poder vê-lo como objeto - mas como, ao mesmo tempo, objeto e sujeito, o que faz com que desde o momento que a gente faz com que o sujeito reapareça, isso vai questionar o sujeito [ele mesmo] sobre a polissemia da sua realidade.

Quer dizer que se a gente questiona o sujeito, na antropologia o sujeito é biológico, ele tem uma identidade biológica e genética, mas ele também é psicológico, ele também é sociocultural e talvez haja uma dimensão espiritual subjacente; então interrogar o sujeito vai subentender ao mesmo tempo interrogar sua relação com os outros sujeitos. Então vai ter um questionamento dentro das relaçóes de intersubjetividade, mas também vai ter uma dimensão intrasubjetiva de algum modo; quer dizer que o nível de realidade do biológico é diferente do nível de realidade do psicológico e ele mesmo é diferenciado em interação com a dimensão sociocultural ou talvez também a espiritual; o que quer dizer que em outras palavras, no nível metodológico, novamente, a gente vai questionar a pessoa - para utilizar o jargão transdisciplinar - sobre os seus diferentes níveis de realidade; e colocar a questão dos níveis de realidade é fundamental, porque a gente vai poder talvez tratar uma pessoa num plano psicológico, mas talvez não no nível biológico, e também o contrário. 
E há muitas confusões na nossa prática, segundo os a priori que temos. Então vocês veem aí, de novo, a fenomenologia, a gente vai considerar que podemos tratar tudo pela oração, ou pela meditação ou pelos remédios ou pela psicologia. E isso é falso! Algumas coisas, claro, podem ser tratáveis, outras não. Por isso é importante problematizar nos diferentes níveis de realidade, porque isso evita um monte de confusôes possíveis.

Então, um nível de realidade é sempre definido por leis muito específicas, porque se houvesse justamente uma confusão destas leis, aí estaremos num sincretismo muito negativo. Apenas para dar para vocês um exemplo, (e eu já estou terminando a minha conferência) um dia estando no meu posto de professor na Universidade de Tours, eu estava dando um curso numa outra cidade e eu cheguei tarde à noite no meu hotel; enquanto eu desfazia minha mala, eu liguei a televisão e tinha ali uma entrevista com uma pessoa que era um cabalista, já faz cinco ou seis anos, era do grupo do qual Madona fazia parte, que usava uma fita vermelha. Ele falava de cabala. Como eu trabalho essas dimensóes mesmo do taoísmo, da cabala, eu tenho muitas pesquisas no campo da antropologia cultural e da antropologia simbólica; então escutei o que a pessoa estava falando e pelo que eu sabia da cabala estava bem coerente; mas num momento este grupo utilizava água para poder tratar as pessoas - água impregnada com letras hebraicas, que tinha propriedades extraordinárias, aí ele falou da estrutura molecular da água (é um discurso que eu também compreendi muito bem, porque eu tenho também um mestrado em biologia molecular), eu fui pesquisador no Instituto Pasteur, entâo são campos que eu também atravessei. Ali ele estava falando uma coisa que também era coerente, mas a telescopagem, a aproximação desses dois campos, um tentando legitimar o outro, sem nenhuma forma de objetividade científica, sem nenhuma forma de metodologia para tentar compreender o que de fato estava acontecendo, isso para mim é um abuso do pensamento. Isso é uma manipulação.

A importância de respeitar as leis e os mundos que nos constituem, que constituem as nossas relações, isso é uma coisa fundamental, o que não quer dizer que se esses níveis de realidade estão separados entre si não possa ha- ver relaçôes e passagens possíveis. Então aí também é preciso metodologicamente apreender como essas passagens ocorrem, como as relaçóes se constituem. Porque a gente poderia, mesmo de maneira simbólica, que as interaçóes entre o nível um e o nível dois, elas não necessariamente vão ser as mesmas relaçóes que as de nível três ou de nível quatro, senão haveria só nível um e dois. Então é preciso problematizar todos esses elementos entre eles, da mesma maneira que é preciso abrir a questão, não só as causas anteriores, mas também em termos de teleologia; quando uma pessoa está doente, a gente vai tratar causas anteriores, mas também o que ela mesma pode sentir da sua doença; em direção a que essa doença a conduz ?!

Isso interroga sobre o sentido profundo da vida. Será que todas as provaçóes que nós atravessamos servem apenas para que a gente volte ao estado anterior quando a gente estava bem? Ou será que cada experiência nos enriquece, nos faz crescer?! Sem, claro, querer estar aqui querendo fazer uma apologia do sofrimento! Em todo caso isto nos coloca questóes; fundamentalmente, a gente nunca volta ao estado anterior.

Então em subjacência a estas questôes há também uma filosofia da medicina que deve ser reconstruída, porque antigamente já existiram pensadores da medicina; mas atualmente nós temos tendência a esquecer dessas dimensóes. E o último ponto, depois a gente vai parar, é a questão sempre nesses questionamentos metodológicos, se a gente postular essas questóes relativas a esses níveis de realidade, que começam a ser adotados também pela ciência, por exemplo, a física quântica que tem leis muito específicas, que não são de modo algum aquelas da física clássica, isto mostra que são diferentes níveis de realidade e quando a gente coloca o questionamento sobre as diferentes culturas tradicionais, a gente vê que todas essas culturas estão apoiadas numa visão do ser humano em diferentes níveis de realidade.

Então a questão que se coloca em termos de fenomenologia é que se estes níveis de realidade existem, quer dizer que temos diferentes maneiras de ver conforme o nível. Podemos ver então as coisas num nível puramente biológico e material, e isso legitima completamente a 
abordagem científica clássica, mas a gente também pode aprender a ver as coisas de outro modo, isso equivale dizer que a cada nível fenomenológico isto esteja ligado a um certo tipo de lógica; por isso, para mim a lógica do terceiro incluído está ligada a um dos níveis de realidade, a lógica do terceiro excluído estaria ligada a outro nível de realidade, mas há ainda outros tipos de lógica. Então em cada nível fenomenológico remete a um nível lógico, isso também remete a um nível ontológico no sentido de um processo ontogenético, ou se vocês preferirem, antropoformador. Quer dizer que justamente em termos de teleologia, ou seja, do sentido profundo de transformaçôes que a gente vive nas nossas experiências de vida, nós somos levados a mudar de posicionamento.

Nós pudemos apreender as coisas a partir de um certo posicionamento num certo momento da nossa vida, mas nós podemos viver rupturas e crises que nos fazem aprender as coisas de maneira diferente mais tarde. Então vejam aí, implicitamente, essa questão de um processo de formação do humano - entấo antropoformador - que inclui um caminho de ontogênese de algum modo com diferentes estaçóes, que nos conduzem a uma certa finalidade, que nós podemos, - mas aos meus olhos, e eu estou falando de mim mesmo, não estou engajando ninguém mais -,considerar isso como inscrito numa dimensão espiritual.

Então vejam que todas essas questôes, de algum modo, vão refundar essa nova abordagem da ciência, em subjacência com uma nova epistemologia, com novas metodologias, e metodologias, por exemplo, sobre as quais não falei e constituíram minha tese de doutorado em Ciências da Educação - a metodologia da tessitura - a metáfora da tessitura é interessante porque a gente fala de tecido a respeito de corpo humano, de tecido em relação às relaçóes sociais, talvez a gente seja constituído de diferentes tipos de tecidos ou metaforicamente de diferentes corpos. Então vejam aí um pouco as questôes que se colocam. Eu espero ter sido o mais simples possível. Eu agradeço a qualidade da escuta de vocês. Se vocês quiserem a gente pode consagrar agora alguns minutos para diálogos.

\section{Pergunta do Prof. Afonso}

Como aqui tem pessoas... campos multiprofissionais, de várias áreas da saúde... Foi comentado na reunião anterior sobre a linguagem, uma forma de trabalhar junto as diferentes áreas. Agora, no sentido prático, como ele falou agora várias vezes no sentido prático e pragmático, quais seriam as outras maneiras para que esse grupo de fisioterapeuta, fonoaudiólogos, psicólogos etc., poderem passar do paradigma multidisciplinar para o inter ou transdisciplinar? Foi comentada a questão da linguagem, na prática haveria outra?

\section{Patrick:}

Eu acredito que, antes de mais nada, numa questáo de mudança de paradigma. Para a pluridisciplinaridade a mudança de paradigma não é essencial, porque é próprio da multi ou da pluridisciplinaridade, é um pouco a reapropriação na sua própria disciplina daquilo que pode ser partilhado em outro espaço; entáo ainda na multi e na pluri a disciplina ainda está no centro. No caso da inter e da transdisciplinaridade a questão é muito mais abissal em dois níveis diferentes. Se a gente refletir simplesmente sobre as definiçóes, inter é o que está entre as disciplinas, porque a gente fala de interdisciplinaridade, a gente está falando daquilo que está entre as disciplinas. E o que está entre as disciplinas? O que vocês pensam? É uma coisa simples. Em parte é o sujeito. Na perspectiva das disciplinas, o que está entre as disciplinas é a fronteira. Como construir uma ciência das fronteiras? Isto é uma bela questão!

Mas efetivamente nessas fronteiras emerge o sujeito também, porque o que está entre as disciplinas, se não é o sujeito, então há uma dupla problemática, o das fronteiras disciplinares, que aí nesse caso já não são fronteiras, mas pontes. E o que pode criar fronteiras entre as disciplinas? E depois a questão do sujeito que reemerge com força... Depois há uma interdisciplinaridade ou fraca ou forte em relação à questão do sujeito. No fundamento mesmo da interdisciplinaridade, que foi construída a partir de uma crítica da pluridisciplinaridade, a dimensão humanista está no cerne do questionamento da inter, mas 
esta questão foi um pouco perdida nessa passagem, para tornar isto mais um questionamento mais disciplinar. São duas interrogaçóes sobre as pontes entre as disciplinas, mas sempre é necessário que sejam respostas pragmáticas; não dá para serem respostas gerais entre tal ou tal disciplina, definir as disciplinas concretas que estão em jogo. Quais são os desafios e quais são as formaçóes do sujeito? Colocar a problemática em primeiro lugar de pesquisa.

Com a transdisciplinaridade é um pouco mais vertiginoso ainda, porque a questão da disciplina é a mesma, quer se trate de inter, pluri ou transdisciplinaridade, é sempre uma relação com as disciplinas. Isto não coloca em questão as disciplinas, o que é colocado em questão é o diálogo entre as disciplinas.

Mas na transdisciplinaridade a etimologia de trans é através e além. Então, o que está através e além das disciplinas? O que atravessa as disciplinas? O que vocês acham? Vocês e eu já demos uma parte da resposta quando respondemos sobre a interdisciplinaridade. É sempre a questão do sujeito!

Simplesmente a questão do sujeito na interdisciplinaridade é tratada num único nível de realidade. Enquanto que na transdisciplinaridade, que postula um através e além, a questão do sujeito se constitui em diferentes ní- veis de realidade. Então isso abre muito essa dimensão do sujeito. Mas que também tem que ser objeto de pesquisa. Postula também que nas pesquisas não nos apoiamos apenas na metodologia hipotético-dedutiva, não apenas nela. Se vocês entenderem bem a metáfora da tessitura, ou da tecelagem, sempre há um fio de urdidura e um fio de trama. Quer dizer que o que vai aparecer está no cruzamento dos campos contraditórios, paradoxais. É preciso tecer cada um desses fios em uma metodologia de pesquisa; por exemplo, cruzar métodos hipotético-dedutivos e métodos indutivos, isso é uma maneira de fazer esse cruzamento, mas há outros.

Neide: pelo que entendi não é só a pesquisa, mas é como pesquisar?

Patrick:

Sim, justamente.

Neide: a pesquisa já é feita

Patrick: sim, mas se a gente não utilizar os bons métodos, a gente não vai ter os bons resultados.

Outra pessoa: os métodos, se eu entendi, são quantitativos e qualitativos de igual importância, mas a pesquisa hoje só considera o quantitativo como de importância...

Patrick: sim, é isso mesmo.

FIM! 